IV Congreso Internacional Estética y Política Poéticas del desacuerdo para una democracia plural 16 y 17 de octubre. Valencia

Doi: http://dx.doi.org/10.4995/CEP4.2019.10288

\title{
Atacar la frontera: la poesía como política en la obra de Francis Alÿs
}

\section{Francisco Javier Méndez Landa}

Doctorando del programa: Arte: Investigación-Producción, Facultad de Bellas Artes de San Carlos de la Universidad Politécnica de Valencia. Investigador y Profesor de Asignatura de la Escuela Nacional de Estudios Superiores (ENES) de la Universidad Nacional Autónoma de México (UNAM), campus Morelia. El presente artículo forma parte de mi investigación doctoral que repara en las formas de representación de la ausencia física del cuerpo humano en el arte contemporáneo mexicano, en este caso por migración. ciudadespiral@gmail.com

\begin{abstract}
Since the late 1990s, the belgian artist located in Mexico, Francis Alÿs (1959) has extrapolated his artistic work by leaving the Historic Center of Mexico City as its main social laboratory, to influence various regions of the world -mainly territories of war, socioeconomic, political and migration-conflict, in an eagerness to imagine realities other than those established through the activation of urban accounts, fables, morals, futile activities and children's games; becoming in various and seemingly innocent metaphors that hide complex and powerful social reflections.

The purpose of the present work is to draw an acupuncture that follows some actions of Francis Alÿs outside the Mexican territory to build a global imaginary from the poetic of his work: in a world governed by hopelessness, and the tensions generated by the borders on the countries, the voice of Alÿs becomes a necessary balm that allows us to visualize other possible solutions to the political conflicts resulting from the independence and the consequent autonomy of a given territory.
\end{abstract}

Keywords: Francis Alÿs. Contemporary art. Mexico. Performance. Frontier. Action art. Territory. Poetics. Politics.

\begin{abstract}
Resumen
Desde finales de los años 90 's el artista belga radicado en México, Francis Alÿs (1959) ha extrapolado su labor artística al abandonar el Centro Histórico de la Ciudad de México como su principal laboratorio social, para incidir en diversas regiones del mundo -principalmente territorios de conflicto bélico, socioeconómico, político y migratorio-, en un afán de imaginar realidades distintas a las establecidas por medio de la activación de relatos urbanos, fábulas, moralejas, actividades fútiles y juegos de niños; deviniendo en variadas y aparentemente inocentes metáforas que esconden complejas y poderosas reflexiones sociales.
\end{abstract}

El presente trabajo plantea trazar una acupuntura que sigue algunas acciones de Francis Alÿs fuera del territorio mexicano para construir un imaginario global desde lo poético de su labor: en un mundo gobernado por la desesperanza, y las tensiones generadas por las fronteras de los países, la voz de Alÿs se vuelve un bálsamo necesario que permite visualizar otras soluciones posibles a los conflictos políticos derivados de la independencia y la consecuente autonomía de un determinado territorio.

Palabras clave: Francis Alÿs. Arte contemporáneo. México. Performance. Frontera. Arte acción. Territorio. Poética. Política. 


\section{Introducción}

Haciendo uso del performance, y más exactamente del andar como su herramienta más incisiva para conocer una región determinada, Francis Alÿs (Amberes, Bélgica, 1959) indaga la delgada -y a veces físicamente invisible, pero políticamente rigurosa línea denominada frontera.

En varios de sus trabajos, Alÿs cuestiona las delimitaciones territoriales que los países autónomos han establecido como sus últimos bastiones de poder. Con gestos modestos en algunos casos, y colosales en otros, el artista belga logra desplegar metáforas sobre las demarcaciones en las que incide; como si Del rigor de la ciencia (Borges, 2012) borgeano se tratara: un territorio real sobre el que se desplanta uno ficticio que calza exactamente sobre el otro.

Estas acciones, aparentemente ingenuas y fútiles, están condenadas casi siempre a ser un fracaso de dimensiones épicas: parece imposible que los gestos sutiles generados por un solo individuo -que a veces es acompañado por la complicidad de los habitantes de los contextos donde incide-, puedan trastocar efectivamente una realidad determinada; pero más allá de su efectividad cuantitativa, vale decir que todos ellos pueden ser entendidos desde otras lógicas:

1. Las obras de Alÿs no están diseñadas a la manera de petardos incendiarios que buscan sacudir consciencias multitudinarias en lo inmediato -como sí pretenden hacerlo los actores políticos que en su turno, buscan alcanzar el poder con el uso de la demagogia-; sino que por el contrario, sus actos intentan construir un imaginario de lo alterno: donde en el mundo ordinario existe una distancia geográfica insalvable, aunada a una política rígida e inclemente; el artista alcanza a visualizar la posibilidad de construir puentes utópicos que efectivamente logran solventar las diferencias.

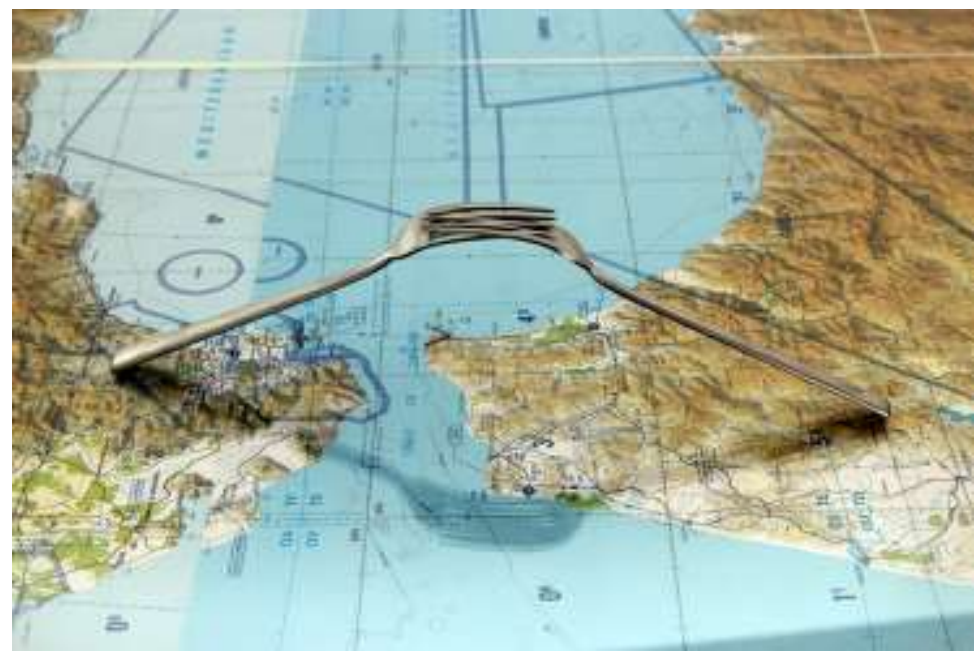

Fig. 1. Francis Alÿs. Mapas, dibujos, notas, fotografías, documentación y esculturas efímeras como base para el proyecto: 'Puentes, 2006-2008'(detalle). 2015. Instalación.

2. La encrucijada bien determinada por el artista entre los polos: político-poético / ético y estético (Boglione, 2014) hace que cada obra no solo funcione en una dimensión estética, sino que busque la forma de incidir en el plano ético; y consecuentemente contaminar con un sentido poético lo político, y también viceversa. Se trata de una Rayuela sobre la que el artista brinca de una casilla a otra activando siempre esos cuatro conceptos, dejándolos a punto, en un calculado equilibrio conceptual.

3. En cada caso, el poder de la obra artística radica en la construcción de un mito, más que en su desarrollo estrictamente documental. Así, el artista prefiere apuntalar un rumor que paulatinamente se consolidará como mito para, por ejemplo, presagiar la existencia de un puente que permita unir físicamente Cuba con los Estados Unidos de Norte América, devolviendo así un atisbo de esperanza a ambos lados del Estrecho de Florida. 
4. La idea de fracaso, contemplada siempre desde el comienzo de los proyectos titánicos que Alÿs emprende puede ser una analogía a las falsas promesas que la política supone (Corvalán, 2014). El artista recurre a la ética para demostrarnos cómo no es humanamente posible tapar el sol con un dedo, y esto, al mismo tiempo, deja al descubierto al político en su intento fallido por probar lo contrario.

\section{De(s)marcar.}

Sobre la frágil línea que constituye la frontera de facto entre Israel y Palestina -la polémica e históricamente cambiante 'Línea verde'-, el artista deambula portando como única arma una lata agujereada de pintura verde, de la cual se le escapa un tímido chorro, dejando tras de sí una estela que marca el tránsito errabundo del artista, pero que al mismo tiempo delimita -de una manera mucho más precisa que en los mapas- el lugar que ocupa efectivamente esa conflictiva frontera.

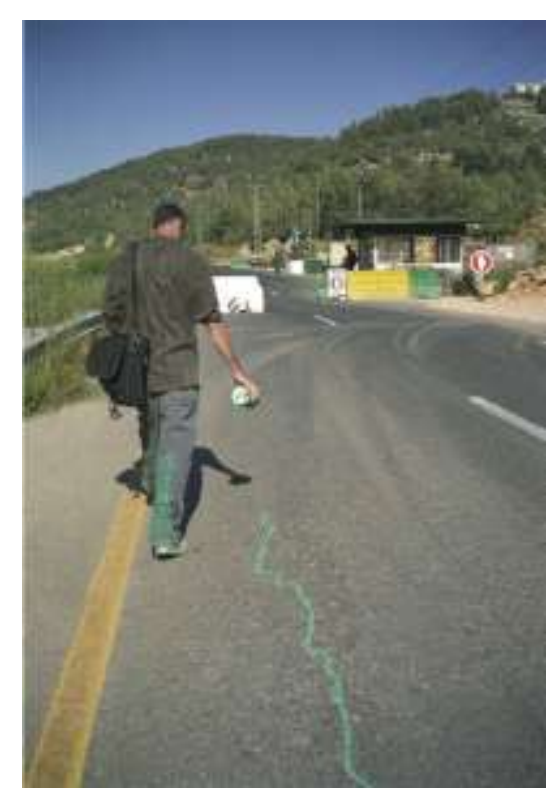

Fig. 2. Francis Alÿs. The green line. 2004. Documentación en video de una acción.

Resulta curioso cómo el artista sale de su estudio para ejercer lo que a primera vista parece ser un acto de action painting, pero que en realidad no tiene la inocencia de las manchas que hacía Pollock sobre un lienzo de grandes dimensiones; sino que su acto es un gesto político al intentar establecer las dimensiones reales de la pintura sobre el territorio mismo.

De nuevo aparece Borges para advertir cómo la línea que Alÿs traza físicamente sobre la tierra, fue anteriormente señalada en 1947 por la Asamblea General de las Naciones Unidas al intentar fallidamente proponer un plan para resolver los conflictos entre árabes y judíos en Palestina, ideando una división territorial señalada a su vez por el ex ministro de defensa Israelí Moshe Dayan con un lápiz verde sobre un mapa a escala 1:20,000 (Alÿs, 2004): la metáfora se despliega como una enorme sábana sobre el territorio de lo real con igualdad de colores y dimensiones. De alguna manera, al chorrear su lata sobre el asfalto, el artista hace más efectiva la frontera que, al estar vagamente marcada en lo físico, se diluye como el mapa descrito por Borges en las inclemencias de los desiertos del Oeste (Borges, 2012).

Con ironía, el artista, apelando a su antiguo oficio como arquitecto, calcula que si la línea fue dibujada con un lápiz graso de 3 a 4 milímetros de grosor, al trazarse sobre un mapa de escala 1:20,000, la anchura de esa línea en realidad representaría unos 60 u 80 metros. ¿Quién gobierna pues ese ancho de línea? (Alÿs, 2004).

Para ser más precisos, el artista recorrería a pie en 2004 la parte de la 'Línea verde’ que atraviesa el municipio de Jerusalén, utilizando para ello 58 litros de pintura verde para conseguir trazar una muralla pictórica de 24 kilómetros de largo (Alÿs, 2004). Eventualmente la línea se borrará, volviendo inútil su gesto, como inútil es tratar de dibujar una línea sobre un 
mapa en un intento de atenuar los problemas entre los vecinos de Oriente Medio. La línea trazada marca una frontera física, pero al mismo tiempo imagina su propia desaparición, al desdibujarse paulatinamente.

\section{3. (entre)Cruzar.}

Para 1997, Francis Alÿs presentaría un singular proyecto en el contexto del inSite, un evento artístico desarrollado periódicamente en la frontera México-Estados Unidos de Norte América. Para esta edición, Alÿs imaginaría una forma de subvertir el fenómeno migratorio para, en vez de cruzar de Sur a Norte la frontera entre México y los Estados Unidos de Norte América, traza una ruta migratoria en el sentido inverso, para ir de Tijuana a San Diego -ciudades limítrofes-, pero por la ruta opuesta, imaginando una nueva forma de migrar: yendo por avión de Tijuana a Ciudad de México, Panamá, Santiago de Chile, Auckland, Sydney, Singapore, Bangkok, Rangún, Hong Kong, Shanghái, Seul, Anchorage, Vancouver, Los Ángeles y finalmente San Diego; todo ello en un trayecto de 35 días que fue alimentado gracias al ir y venir de correspondencia postal entre el artista y el comité curatorial del inSite.

Con esta acción, el artista, al igual que Marco Polo, genera una nueva ruta para la inmigración que va en contra de la lógica misma de la migración al optar por no cruzar por el estrecho más angosto. En este sentido, Alÿs imagina una nueva ruta que comenzaría en Tijuana, México, y que culminaría en San Diego, California. Lo que puede traducirse en una caminata a pie de poco más de un kilómetro, recorrido en poco menos de treinta minutos, se convierte en una odisea que involucra la participación de al menos catorce países en más de un mes, y que es, a todas luces, un proyecto económicamente inviable para todo migrante deseoso de cruzar la frontera.

Por supuesto que, para poder emprender este viaje, el paseante deberá necesariamente estar inscrito en la legalidad, por lo que nuevamente este hallazgo se vuelve inútil en lo práctico, pero poderosamente efectivo en el imaginario colectivo al encontrar un nuevo tránsito para arribar al país vecino: lograr traspasar la frontera sin estrictamente cruzarla.

\section{4. (re)Unir.}

La noción de frontera posee para Alÿs una condición de maleabilidad, que puede definitivamente disolverse o revelarse, dilatarse o contraerse según el caso; pero para aquellas separaciones territoriales donde además de la geografía, la política migratoria de cada país hace aún más insalvables las distancias, el artista decíamos, logra ver puentes flotantes que logran unir dos países.

Se trata de dejar de pensar por un minuto en el mar, como la marea líquida que es, para volverse una plataforma cristalina, como la que sirvió para enlazar Siberia con Alaska: superficie firme; un muro de Berlín que se disuelve; la posibilidad de nuevamente abrazarse, y de dejar estampado en el imaginario la idea de que, al menos por un breve instante, esa tenue ilusión se consolida. Al mismo tiempo, se vuelve necesaria la reconceptualización de la palabra 'puente' y las formas no ortodoxas de construirlos.

\subsection{Cayo Hueso (EUA) - La Habana (Cuba)}

En 2005, Alÿs comenzaría un proyecto de largo aliento sobre una premisa muy simple: convocar a lancheros tanto de Cayo Hueso, Florida, como de La Habana, Cuba, a alinear sus barcas para construir un puente sobre el mar que lograra por fin enlazar estos dos países y minimizar por un instante el histórico bloqueo binacional.

Resulta sencillo imaginar el funesto resultado: Alÿs escribe en su diario que: 'el 29 de marzo de 2006, 150 barcos se alinearon desde Cayo Hueso, Florida y Santa Fe de la Habana para proyectar un puente flotante entre Cuba y los Estados Unidos' (Medina, et al. 2007). Evidentemente, las pocas embarcaciones que se dieron cita -más de cien del lado cubano, contra poco más de treinta del lado estadounidense- (Alÿs, et al. 2015), no bastaron para cubrir los 170 kilómetros que separan los dos puntos nodales del proyecto; y aunque ese puente no puede existir más que en la mente del hombre, el artista sembró una idea contundente en una zona geográfica hambrienta de esperanza, y nuevamente, instauró la mitología 
de que una comunidad pudo materializar un puente mediante la precisa coordinación de sus actores; algo que la política feroz de estas naciones ha imposibilitado consolidar durante décadas; y este puente se vuelve paradójicamente más sólido y tangible que los cientos de promesas y palabras vacuas dictadas por los gobernantes.
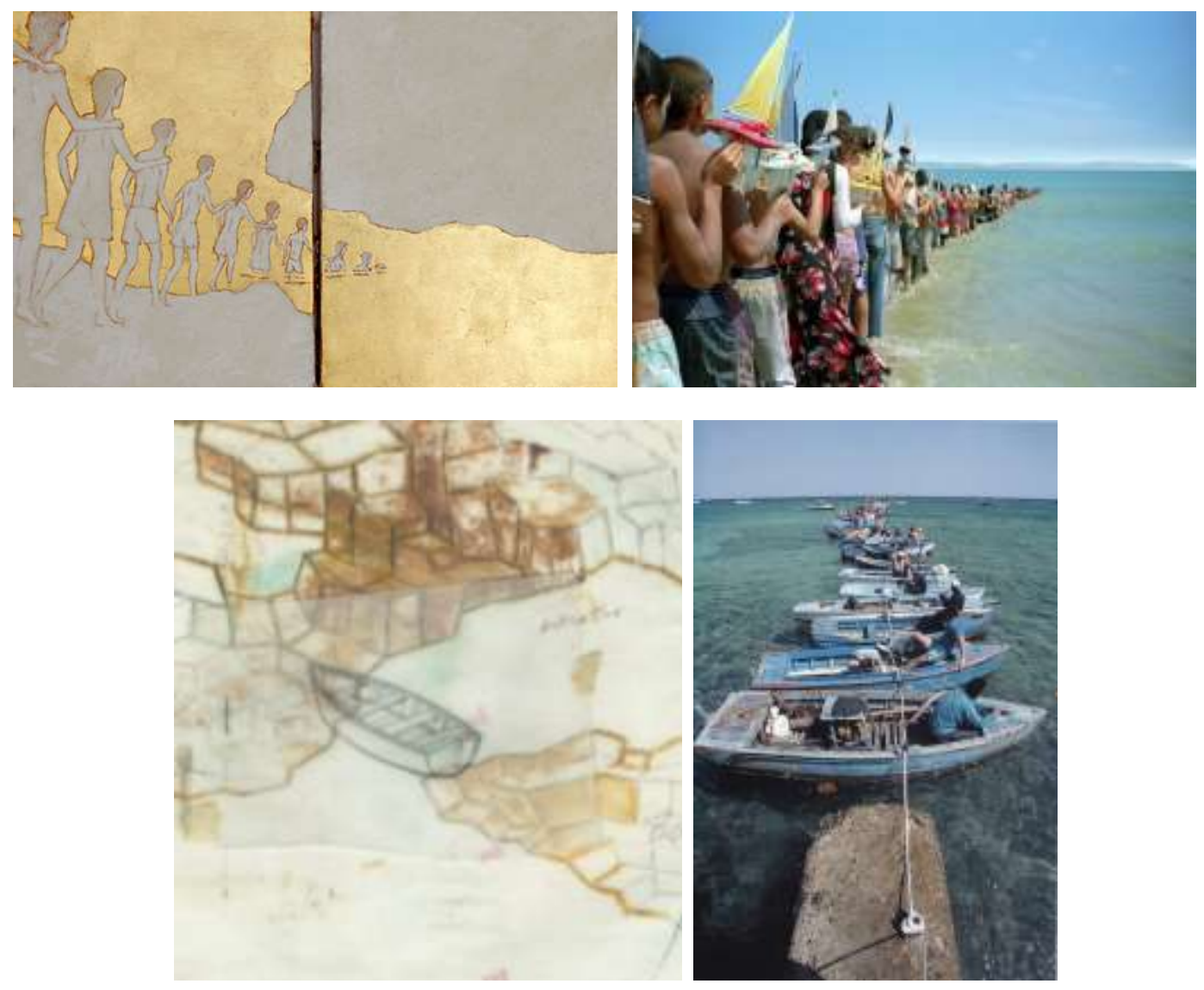

Fig. 4 (izquierda). Francis Alÿs. Estudio para Bridge/Puente (detalle). 2006. Lápiz y óleo sobre papel albanene. Fig. 5 (derecha). Francis Alÿs. Bridge/Puente. 2006. Documentación en video de una acción.

\subsection{Tánger (Marruecos) - Tarifa (España)}

El 12 de agosto de 2008, Alÿs materializaría otro poético puente. Si la separación entre La Habana y Cayo Hueso es de 170 kilómetros, la distancia que existe entre Marruecos y España es de tan sólo 14. Desde las costas de estos países, es posible ver las costas vecinas. Según los cálculos de Alÿs, para salvar esta distancia se requerirían aproximadamente 72 barcos de carga (Alÿs, et al. 2015), lo cual constituye una operación logísticamente más sencilla que en el caso de Cuba, pero al mismo tiempo, ejecutar esta acción con barcos reales significaría sencillamente construir un acto utilitario; convirtiéndose más en una empresa de ingeniería que en un gesto propiamente artístico. (Alÿs, et al. 2015).

Aquel día de agosto, las aguas del Estrecho de Gibraltar impulsaron una cadena de cientos de pequeños barcos manufacturados a partir de zapatos y sandalias, cruzando de Tánger a Tarifa y viceversa, gracias a una cadena de niños que iban pasando uno a uno el barco que iba a ser liberado por el niño que se encontraba en la punta de la línea, dentro del mar, a cada lado del Estrecho. Aquí lo poético -que no lo efectivamente redentor de atravesar un continente hasta llegar a tierra firme- ocurre en la imagen creada por el artista: una centena de pasos que irremediablemente habrían de disolverse en el agua, en su desdichado afán de llegar a la otra orilla donde aguarda la promesa de un mejor futuro.

Fig. 6 (izquierda). Francis Alÿs. Estudio para Don't cross the bridge before you get to the river. 2008. Encáustica y óleo sobre lienzo y madera. 
Fig. 7 (derecha). Francis Alÿs. Don't cross the bridge before you get to the river. 2008. Documentación en video de una acción.

Como puede verse, en todos los casos, el artista ataca la noción más clásica de una frontera como la separación efectiva de un Estado, para contarnos, a la manera de un cuento de niños, las fábulas de una tribu que pudo traspasar los límites impuestos por una sociedad determinada, volviendo solubles estas líneas que para el artista, deberían ser abolidas ahorrando así una incontable cantidad de muertes globales por el intento de traspasarlas.

Ilusamente, vivir en un mundo sin fronteras, o al menos, en un mundo donde todos los habitantes del planeta puedan tener el acceso a cruzarlas en cualquier sentido y por cualquier motivo, es la utopía que Alÿs intenta volcar en sus acciones, pero más allá de construir caminos desde el activismo legal, donde seguramente sus actos serían todavía más inútiles; el artista recurre al arte como una herramienta para establecer caminos esperanzadores donde, a partir de una sociedad organizada, es finalmente posible alcanzar la otra orilla. El problema -dice Alÿs- no es contar historias, inventar imágenes o crear fábulas, el problema es cuando uno comienza a creérselas (Alÿs, et al. 2015), para a partir de allí, establecer un nuevo imaginario.

\section{Referencias}

AlŸs, F., Medina, C., TAussig, M. (2015). Francis Alÿs: Relato de una negociación. Una investigación sobre las actividades paralelas del performance y la pintura. Ciudad de México: Instituto Nacional de Bellas Artes y Literatura.

Boglione, R. (2014). "Viejas y nuevas paradojas de la praxis" en La diaria. Buenos Aires, 7 de agosto de 2014. <https://ladiaria.com.uy/articulo/2014/8/viejas-y-nuevas-paradojas-de-la-praxis/> [Consulta: 8 de agosto de 2019].

Borges, J. (2012). El hacedor. Ciudad de México: Debolsillo.

CorvalÁn, K. (2014). "Francis Alÿs: el pequeño gesto es un gesto político" en Leedor. Buenos Aires, 9 de agosto de 2014. <http://leedor.com/2014/08/09/francis-alys-el-pequeno-gesto-personal-es-gesto-politico/> [Consulta: 8 de agosto de 2019].

FRANCIS ALŸS, "Bridge/Puente”. Vimeo <https://vimeo.com/130897954> [Consulta: 9 de agosto de 2019].

FRANCIS ALŸS, "Don't cross the bridge before you get to the river". Vimeo < https://vimeo.com/130921406 > [Consulta: 10 de agosto de 2019].

FRANCIS ALŸS, "The green Line". Vimeo < https://vimeo.com/132929393 > [Consulta: 8 de agosto de 2019].

KlichmanN, P. (1997). "Francis Alÿs" en Peter Klichmann Gallery. Zurich <http://www.peterkilchmann.com/artists/francisalys/overview/the-loop-1997> [Consulta: 10 de agosto de 2019].

Medina, C., Ferguson, R., Fisher, J. (2007). Francis Alÿs. Londres: Phaidon. 